\title{
Association of anti-sperm antibodies with chronic prostatitis: a systematic review and meta-analysis
}

Yumei Jiang ${ }^{1}$ Dong Cui ${ }^{1}$ Yuefeng $\mathrm{Du}^{1}$, Jun $\mathrm{Lu}^{1}$, Lin Yang ${ }^{1}$, Jinmei $\mathrm{Li}^{1}$, Jing Zhang ${ }^{1}$, Xiaojing $\mathrm{Bai}^{1}{ }^{*}$

1. Department of Urology, First Affiliated Hospital of Xi'an Jiaotong University, Xi'an, Shaanxi, 710061, China.

Yumei Jiang and Dong Cui contributed equally to this work.

*Corresponding author. E-mail: 524089802@qq.com.

\begin{abstract}
Chronic prostatitis is a risk factor for impaired male fertility potential, and anti-sperm antibodies (ASAs) cause the autoimmune disease immune infertility, which has a negative effect on semen parameters. Current studies have investigated the ASA-positive relationship between chronic prostatitis versus normal controls, but have shown inconsistent results. Hence, we systematic searched the PubMed, EMBASE, Science Direct/Elsevier, Medline, and the Cochrane Library up to October 2015 for case-control studies that involved the ASA-positive relationship between chronic prostatitis patients versus normal controls. The meta-analysis was performed with Review Manager and Stata software. After literature search, six studies were identified, including 721 cases of chronic prostatitis and 160 normal controls. Our results illustrated a significant correlation of the ASA-positive relationship between chronic prostatitis patients versus normal controls. The combined odds ratio of the ASA-positive rate in chronic prostatitis patients and normal controls was 3.26 (1.86-5.71). There was also a significant correlation of the ASA-positive relationship between National Institutes of Health (NIH) III versus normal controls, and the combined OR was 2.46 (1.10-5.51). However, there was no significant correlation of the ASA-positive relationship between National Institutes of Health (NIH) II versus normal controls. The present study
\end{abstract}


illustrates that the positive rate of ASAs in chronic prostatitis patients was significantly higher than in the control group, suggesting that chronic prostatitis has a negative effect on male reproductive function. However, studies with larger samples are needed to better illuminate the correlation between ASAs and chronic prostatitis.

Key words: anti-sperm antibody, chronic prostatitis, male infertility

\section{Introduction}

Prostatitis is the most common urological disease in men under the age of 50 years, with prevalence ranging from $2.2 \%$ to $9.7 \%$ worldwide, with an overall rate of $8.2 \%$ (Krieger et al., 2008). It is defined as a heterogeneous mixture of syndromes, with broad diagnostic criteria but its etiology and pathophysiology are somewhat vague (Sharp et al., 2010; Pontari et al., 2008). The prostate is a male accessory sex organ that provides secretions vital for normal fertility. It secretes several major components of seminal plasma that nourish and protect spermatozoa following ejaculation. The current study considered the prostate to be an immunocompetent and not an immunoprivileged site as previously thought (Whitmore et al., 1977; Kramer et al., 2001). Given the intimate association of the prostate with male reproductive function, prostatitis has long been suspected of playing a role in male subfertility. But strong evidence for a direct impact of prostatitis on male fertility is lacking.

Research on anti-sperm antibodies (ASAs) began in 1899, when it was initially reported that sperm could be antigenic if injected into a foreign species (Landsteiner et al., 1899). The presence of ASAs in infertile men was first reported by Rumke et al. (1954) and Wilson 
et al. (1954). Since then, ASAs have been considered by several authors as a possible causative factor in infertility, with significant levels being detected in the semen of 5-15\% (Adeghe et al., 1993) of infertile men but in only 1-2\% (Ayvaliotis et al., 1985; Bates et al., 1997) of fertile men. It is assumed that the development of ASAs is mainly a consequence of trauma to the blood-testis barrier, epididymis, or vas deferens (Gubin et al., 1998). ASAs is also associated with inflammation, and their appearance is often thought to be of idiopathic origin (Lenzi et al., 1997).

Current studies have investigated the correlation between the presence of ASAs and chronic prostatitis, but have shown contradictory results. Some studies have shown a significant ASA-positive relationship in patients with chronic prostatitis compared with healthy individuals (Hoover et al., 2012; Marcelo et al., 2009; Puxin et al., 2009), but not other studies (Chunhua et al., 1992; Su Qin et al., 2005; Jianguo et al., 2004). Therefore, we systematically reviewed the available literature and performed a meta-analysis to evaluate the correlation of ASAs and chronic prostatitis, which might shed valuable insights into the relationship between chronic prostatitis and male infertility.

\section{Methods}

\section{Literature search}

This meta-analysis was restricted to published studies that investigated the ASA-positive relationship between chronic prostatitis versus normal controls. Two independent reviewers (Jiang YM and Cui D) searched PubMed, EMBASE, Science Direct/Elsevier, Medline, CNKI, and the Cochrane Library from inception to December 
2014. The language or study type was not restricted. The search terms combined text words and MeSH terms. For example, the search terms for ASAs were: 'antisperm antibodies', 'sperm antibodies', 'antibodies', 'ASAs', and 'semen antibodies', while those for chronic prostatitis were: 'prostatitis', 'prostatism', 'chronic prostatitis', 'chronic pelvic pain syndrome', 'abacterial prostatitis', 'bacterial prostatitis', and 'prostatodynia'. All related articles and abstracts were retrieved. In addition, references cited within relevant reviews were retrieved by hand, and only full articles were searched.

\section{Eligibility criteria}

Studies were included if patients met the diagnostic criteria of chronic prostatitis. The classification of prostatitis syndrome followed the consensus criteria of the National Institutes of Health (NIH). I: acute bacterial prostatitis; II: chronic bacterial prostatitis; III: chronic prostatitis/chronic pelvic pain syndrome; and IV: asymptomatic inflammatory prostatitis. The controls were healthy men with no history or evidence of andrologic or urologic disease. ASAs were detected by a sperm anti-sperm antibody test [mixed agglutination reaction (MAR), immunobead test (IBT), or enzyme-linked immunosorbent assay (ELISA)]. Available data were extracted from the article, including numbers of cases and controls, and the ASA-positive rate in all case-control groups.

\section{Exclusion criteria}

Studies were excluded if they were case reports or review articles. Studies involving patients with chronic prostatitis accompanied by other disorders of the urogenital system, and patients who had previously undergone surgery of the genital system were also 
excluded.

\section{Study selection and validity assessment}

Two independent reviewers (Jiang YM and Du YF) screened titles and abstracts of all citations from the literature search. All relevant studies that appeared to meet eligibility criteria were retrieved. If an ambiguous decision was made based on the title and abstract, full texts were needed. The final decision about eligible studies was made by reviewing the articles. Disagreements were resolved by consensus or a third reviewer (Lu J). Two reviewers (Yang Lin and Li JM) completed the quality assessment according to the primary criteria for non-randomized and observational studies of the Newcastle-Ottawa Quality Assessment scale, a tool used for assessing the quality of non-randomized studies included Using the tool, each study is judged on eight items, categorized into three groups: the selection of the study groups; the comparability of the groups; and the ascertainment of either the exposure or outcome of interest for case-control or cohort studies respectively. In meta-analysis, stars awarded for each quality item serve as a quick visual assessment. Stars are awarded such that the highest quality studies are awarded up to nine stars.

\section{Data extraction and statistical analysis}

Data, including demographic data (authors, year of publication, country, number and mean age of participants, and assay method) and outcome data of ASA-positive patients in all case-control studies, were extracted by two reviewers (Zhang J, and Li JM). Disagreements were resolved by consensus. Quantitative meta-analysis was performed by 
three reviewers (Jiang YM, Cui D and Bai XJ) with Review Manager (RevMan) version 5.2 (Nordic Cochrane Centre, Cochrane Collaboration, 2012, Copenhagen, Denmark) and Stata version 12.0 (College Station, TX, USA). Available data were analyzed by meta-analysis. To understand better the ASA-positive relationship between chronic prostatitis patients versus normal controls, sub-analysis was performed simultaneously.

In order to calculate combined OR and its 95\% confidence interval (CI). Heterogeneity was assessed by $\mathrm{P}$ value and $I^{2}$ statistics in the pooled analyses, which represents the percentage of total variation across studies. If $\mathrm{P}$ was $<0.1$ or $I^{2}$ was $>50 \%$, the summary estimate was analyzed in a random-effects model. Otherwise, a fixed-effects model was applied. In addition, publication bias was detected by visual symmetry of funnel plots, with asymmetry suggesting possible publication bias. It was also assessed by the Begg's and Egger's tests in the meta-analysis. The Begg adjusted rank correlation test is a direct statistical analogue of the visual funnel graph. The Begg procedure tests for publication bias by determining if there is a significant correlation between the effect estimates and their variances. Asymmetry on the right of the graph (where studies with high standard error are plotted) may give evidence of publication bias. The Egger test detects funnel plot asymmetry by determining whether the intercept deviates significantly from zero in a regression of the standardized effect estimates against their precision. If $\mathrm{P}$ was $<0.05$, publication bias existed.

\section{Results}

Characteristics of the included studies 
Figure 1 shows the detailed review process. A total of 1173 unduplicated studies were identified. Six studies were ultimately selected according to the eligibility criteria; three studies investigated a relationship between the ASAs and NIH II, and three investigated a relationship between the ASAs and NIH III. After group discussion, all reviewers were in agreement to include all six papers.

Table 1 summarizes the data from the six studies. All retrieved studies involved 721 cases and 160 controls. The mean ages of patient and control groups were in the ranges of 29.5-36.5 and 29.7-39.6 years, respectively. The mean ages of the patient and control groups were unavailable for two studies. All of these studies reported exclusion/inclusion criteria (Hoover et al., 2012; Marcelo et al., 2009; Chunhua et al., 1992; Su Qin et al., 2005; Jianguo et al., 2004; Puxin et al., 2009). Three of these studies (Marcelo et al., 2009; Su Qin et al., 2005; Puxin et al., 2009) detected ASAs by MAR, and included 578 patients with chronic prostatitis and 109 normal controls. Two studies (Chunhua et al., 1992; Jianguo et al., 2004) detected ASAs by ELISA, including 123 cases and 31 normal controls. One study (Hoover et al., 2012) detected ASAs by IBT test, including 20 cases and 20 controls.

\section{Meta-analysis}

The test of heterogeneity suggested a fixed-effect model and the meta-analysis revealed a significant correlation of the ASA-positive relationship between chronic prostatitis patients versus normal controls, with an overall combined OR of 3.26 (95\% CI: 1.86-5.71) (Figure 2). Sub-analysis was performed simultaneously. There was also a significant correlation of the ASA-positive relationship between NIH III versus normal 
controls, with a combined OR of 2.46 (95\% CI: 1.10-5.51) (Figure 3). However, there was no significant correlation of the ASA-positive relationship between NIH II versus normal controls, with a combined OR of 1.46 (95\% CI: 0.50-4.22) (Figure 3). There was no evidence of significant heterogeneity among these studies $\left(\mathrm{P}>0.1, I^{2}<50 \%\right)$. The six studies analyzed in this systematic review were heterogeneous in terms of ASAs test type (IBT, MAR, and ELISA). Although the World Health Organization recommends MAR and IBT, two studies detected ASAs by ELISA. Therefore, we conducted sub-analysis (Figure 4) getting rid of ELISA test or getting rid of IBT test, but the final conclusion were not changed (the ASA-positive rate in chronic prostatitis patients was higher than in healthy individuals). Begg's funnel plot were largely symmetric (Figure 5), suggesting that there were no publication biases in the meta-analysis. Egger's regression test also indicated little evidence of publication bias $(\mathrm{P}=0.683)$. We also conducted a sensitivity analysis of the meta-analysis. We omitted one study sequentially, and the calculated combined ORs for the remaining studies yielded consistent results. In the overall meta-analysis, no single study significantly changed the combined results, which indicated that the results were statistically stable and reliable (Figure 6).

\section{Discussion}

Six studies investigated the ASA-positive relationship between chronic prostatitis patients versus normal controls. Only three studies (Chunhua et al., 1992; Su Qin et al., 2005; Jianguo et al., 2004) reported a significant correlation. In our meta-analysis, there was a significant correlation of the ASA-positive relationship between chronic prostatitis 
versus normal controls (Figure 2). To understand better the correlation of the ASA-positive relationship between chronic prostatitis versus healthy male, we performed a sub-analysis simultaneously. Three out of six studies investigated the correlation of ASAs and NIH III, but only one study clearly reported a significant correlation. Our results suggest a significant ASA-positive rate between NIH III versus normal controls (Figure 3); however, the other three studies investigated the correlation of ASAs and NIH II. All these studies showed no significant correlation, which is identical with our meta-analysis.

Male infertility is a complex clinical syndrome, and its incidence has shown an increasing trend in recent years (Liu et al., 1992). Prostate fluid is one of the nutritional components for sperm, and it provides primary energy for sperm activity (Jianning et al., 1992), and prostate disease inevitably affects the quality of semen. Prostatitis and male infertility have been disputed for many years, but strong evidence for a direct impact of prostatitis on male fertility is lacking.

Many studies have confirmed that ASAs has a negative effect on sperm parameters. It can reduce sperm concentration and motility and prolong semen liquefaction (Rossato et al., 2005; Armand et al., 2010; Armand et al., 2011; Dona et al., 1987; Patricia et al., 2007). ASAs has been used to explain unexplained infertility. Sperm ASAs are believed to have an adverse impact on male reproduction function, ASAs production is directed against spermatic surface antigens (Steen et al., 1994; Mazumdar et al.,1998), interfering with sperm motility and transport through the female reproductive tract and inhibiting capacitation and acrosome reactions (Bronson et al.,1990; Steen et al., 1994). On the other hand, ASAs have an indirect mechanism of action to mediate the release of cytokines which 
affect sperm function and impair sperm-cervical mucus interaction (Sinisi et al., 1993; Mazumdar et al., 1998; Lombardo et al., 2001), induce sperm cytotoxicity, increase sperm phagocytosis or inhibit embryo development and implantation. As result, natural pregnancies rates decrease. (Marshburn et al., 1994; Vivas et al., 2007; Oliveros et al., 2000; Jaimes et al., 1984).

In humans, ASAs production is due to auto-antigenic and iso-antigenic properties of spermatozoa. The blood-testis barrier and integrity of the genitourinary tract isolate spermatogenesis from the immune system. Therefore, the ASA-positive rate is lower. When the genitourinary tract is damaged, such as by inflammation induced through genital infection or other disease, the integrity of the genitourinary tract is breached, and the immune system may produce ASAs. Batstone et al. (2002) have found lymphocyte infiltration in the semen of patients with autoimmune prostatitis. In humans, there is a phenomenon of semen prostate liquid reflux. In healthy male, the quality of semen parameters may not change, but in chronic prostatitis patients there may be a negative effect upon the sperm parameters (Weidner et al., 1991; Engeler et al., 2003; Ausmees et al., 2013; Motrich et al., 2006; Motrich et al., 2005; Leib et al., 1994; Henkel et al., 2006). This suggests that the integrity of the genitourinary tract is damaged in chronic prostatitis.

Several risk factors are involved in pathogenesis of infertility, and ASAs are just one of them. The current studies have confirmed that ASAs (Rossato et al., 2005; Armand et al., 2010; Armand et al., 2011; Dona et al., 1987; Patricia et al., 2007) and chronic prostatitis (Engeler et al., 2003; Ausmees et al., 2013; Motrich et al., 2006; Motrich et al., 2005; Leib et al., 1994; Henkel et al., 2006; Menkveld et al., 2003; Pasqualotto et al., 2000) influence 
a negative effect upon semen parameters. In our study, the ASA-positive rate in chronic prostatitis patients was significantly higher than in the control group, which suggests that chronic prostatitis may have an effect on semen parameters through ASAs, but further studies are required. For evaluation of the risk of infertility in NIH III patients, detection of ASAs in seminal fluid may be important.

There were some limitations to our study that need to be taken into consideration when interpreting the results of this meta-analysis. First, the inherent limitations of the studies included in this analysis are the different ASAs assaying methods (IBT, MAR, and ELISA). However, our sub-analysis suggested that the different methods applied did not change the final conclusion. The Sensitivity and specificity of the different assays are lacking in the related studies. And it is unclear which proportion of ASAs binds to clinically relevant antigens and leads to infertility (Bohring et al., 2003; Ohl et al., 1995). IBT, MAR, and ELISA tests may provide a crude assessment of the correlation of ASAs in chronic prostatitis patients, and this may influence how one interprets correlation studies with chronic prostatitis and male immunological infertility. Second, the sample size of each study was relatively small, and a total of 721 chronic prostatitis patients and 160 normal controls were investigated in all six studies. Furthermore, several studies related to the topic were excluded owing to a lack of control data. As such, it is hard to make definitive conclusions about the clinical value of chronic prostatitis and immunological infertility.

In summary, the results of this meta-analysis suggest that the ASA-positive rate (as measured by MAR, IBT, and ELISA) was higher in chronic prostatitis patients than in healthy individuals. Our study did not indicate that ASAs or chronic prostatitis always 
results in immunological infertility. ASAs alone have a poor correlation with in vitro fertilization or intracytoplasmic sperm injection pregnancy rates (Nagy et al., 1995; Esteves et al., 2007; Vujisic et al., 2005; Clarke et al., 2006), but in current studies the ASAs negative effect on semen parameters has been confirmed. The negative effect of chronic prostatitis on male reproductive function may be mediated by its toxic influence on semen, as well as through ASAs. Our results add new evidence to the correlation between chronic prostatitis and male reproductive function. And this field was in interest of many investigators. However well-designed studies with larger sample sizes and more appropriate ASAs assays are required to further address this issue. 


\section{Acknowledgements}

The present study was supported by the National Science Foundation of China (grant No. 81072107 and 81372736$)$. 
Table 1.Characteristics of included studies investigating the ASAs in chronic prostatitis patients

\begin{tabular}{|c|c|c|c|c|c|c|c|c|c|c|}
\hline Study & Country & $\begin{array}{c}\text { Mean } \\
\text { age(case/control) }\end{array}$ & Assay & Control & $\begin{array}{l}\text { Case } \\
\text { (CAP) }\end{array}$ & $\|$ & III & IIla & $\mathrm{IIlb}$ & OR $\quad(95 \% \mathrm{CI}$ \\
\hline Mie PX. 2009 & China & $36.5 / 39.6$ & MAR & 34 & 114 & 42 & & 34 & 38 & $1.00[0.31,3.18]$ \\
\hline P.Hoover. 2012 & America & $\mathrm{NI} / \mathrm{NI}$ & IBT & 20 & 20 & 6 & 14 & & & $5.54[0.25,123.08$ \\
\hline Marcoin M. 2009 & Germany & $\mathrm{NI} / \mathrm{NI}$ & MAR & 45 & 310 & 38 & & 59 & 213 & $2.87[0.38,22.00]$ \\
\hline Zhang JG. 2004 & China & $27.5 / \mathrm{NI}$ & ELISA & 20 & 86 & & 86 & & & $5.67[1.55,20.75]$ \\
\hline Deng CH .1992 & China & $30.5 / 29.7$ & ELISA & 11 & 37 & & & & & $5.91[1.12,31.20]$ \\
\hline Qin S. 2005 & China & $29.5 / \mathrm{NI}$ & MAR & 30 & 154 & 28 & & 83 & 42 & $3.90[1.51,10.06]$ \\
\hline
\end{tabular}

Abbreviations: NI not indicated in studies.

\section{Figure legends}

Figure 1. Flow diagram of selection of eligible studies. After Literature search, a total of 1173 unduplicated studies were identified. Six studies were ultimately selected according to the eligibility criteria.

Figure 2. Forest plot showing the meta-analysis outcomes of the ASA-positive relationship between chronic prostatitis patients and normal controls. The results show that the positive rates of ASAs in chronic prostatitis patients were significant higher than normal controls (P $<0.0001)$.

Figure 3 Forest plot of sub-analysis showing the meta-analysis outcomes of the ASA-positive relationship between chronic prostatitis patients versus normal controls. There was also a significant correlation of the ASA-positive relationship between NIH III versus normal controls $(\mathrm{P}=0.03)$. However, there was no significant correlation of the ASA-positive relationship between NIH II versus normal controls $(\mathrm{P}=0.49)$.

Figure 4 Forest plot of sub-analysis showing the influence of different assay methods on meta-analysis. Sub-analysis results show that gets rid of ELISA test $(\mathrm{P}=0.007)$ or gets rid of IBT test $(\mathrm{P}<0.0001)$, but the final conclusion were not changed (the ASA-positive rate in chronic prostatitis patients was higher than in healthy individuals).

Figure 5 Begg's publication bias plot of included studies. The funnel plot of include studies indicates little evidence of publication bias.

Figure 6 Sensitivity analysis plot of association of antisperm antibodies with chronic 
prostatitis. Omitting one study sequentially, no single study significantly changed the combined results.

\section{References}

Adeghe, JH., 1993. Male subfertility due to sperm antibodies: a clinical overview. Obstet. Gynecol. Surv. 48, 1-8.

Ayvaliotis, B., Bronson, R., Rosenfeld D, Cooper, G., 1985. Conception rates in couples where autoim-munity to sperm is detected. Fertil. Steril. 43, 739-742.

Zini, A,, Phillips S., Lefebvre, J., Baazeem, A., Bissonnette, F., Kadoch, IJ., et al., 2010. Anti-sperm antibodies are not associated with sperm DNA damage: a prospective study of infertile men. J. Reprod. Immunol. 85, 205-208.

Zini, A., Lefebvre, J., Kornitzer, G., Bissonnette, F., Kadoch, IJ., Dean, N., et al., 2011. Anti-sperm antibody levels are not related to fertilization or pregnancy rates after IVF or IVF/ICSI. J. Reprod. Immunol. 88, 80-84.

Ausmees, K., Korrovits, P., Timberg, G., Punab, M., Mandar, R., 2013. Semen quality and associated reproductive indicators in middle-aged males: the role of non-malignant prostate conditions and genital tract inflammation. World. J. Urol. 31, 1411-1425

Bates, CA., 1997. Antisperm antibodies and male subfertility. Br. J. Urol. 80, 691-697.

Batstone, GR., Doble, A., Gaston, JS., 2002. Autoimmune T cell responses to seminalplasmain chronic pelvic pain syndrome CPPS). Clin. Exp. Munol. 128, 302-307.

Bohring, C., Krause, W., 2003. Immune infertility: towards a better understanding of sperm autoimmunity. The value of proteomic analysis. Hum. Reprod. 18, 915-924.

Bronson, RA., Fusi, F., Cooper, GW., 1990. Phillips DM. Antisperm antibodies induce polyspermy by promoting adherence of human sperm to zona-free hamster eggs. Hum. 
Reprod. 5, 690-696.

Clarke GN., 2006. Association between sperm autoantibodies and enhanced embryo implantation rates during in vitro fertilization. Fertil. Steril. 86, 753-754.

Deng, CH., Yang, H., Mai, GJ., Zhang, XW., Zhang, YJ., Feng, HM., Li, SQ., 1992. The research of chronic prostatitis and antispermantibody in serum and seminal plasma. Journal of Andrology. 6, 208-211.

Esteves, SC., Schneider, DT., Verza, SJ., 2007. Influence of antisperm antibodies in the semen on intracytoplasmic sperm injection outcome. Int. Braz. J. Urol. 33, 795-802.

Engeler, DS., Hauri, D., John, H., 2003. Impact of prostatitis NIH IIIB (prostatodynia) on ejaculate parameters. Eur. Urol. 44, 546-548.

Gubin, DA., Dmochowski, R., Kutten, WH., 1998. Multivariant analysis of men from infertile coupleswith and without antisperm antibodies. Am. J. Reprod. Immunol. 39, 157-160.

Hoover, P., Naz, RK., 2012. Do men with prostate abnormalities (prostatitisbenign prostatic hyperplasia/prostate cancer) develop immunity to spermatozoa or seminalplasma? international journal of andrology. 63, 608-615.

Henao, IS., Cadavid, AP., Ossa, JE., 1997. Autoanticuerpos antisperm atozoidese infertilidad. Iatreia. 10, 52-59.

Henkel, R., Ludwig, M., Schuppe, HC., Diemer, T., Schill, WB., et al. 2006. Chronic pelvicpain syndrome/chronic prostatitis affect the acrosome reaction in human spermatozoa. World. J. Urol. 24, 39-44.

Jaimes, K., Hargreave, TB., 1984. Immunosuppression by semi-nal plasma and its possible 
clinical significance. Immunol. Today. 5, 352-63.

Krieger, JN., Lee, SW., Jeon, J., Cheah, PY., Liong, ML, et al., 2008. Epidemiology of prostatitis. Int J Antimicrob Agents 31 (Suppl 1), S85-90.

Kramer, G., Dieter, M., Marberger, M., 2001. Is benign prostatic hyperplasia (BPH) an immune inflammatory disease? Euro. Urol. 51, 1202-1216.

Landsteiner, K., 1899. Kenntnis der spezifisch auf blutkörperchen wirkende sera. Zentralbl. Bakt. 25, 546-549.

Lenzi, A., Gandini, L., Lombardo, F., Rago, R., Paoli, D., Dondero, F., 1997. Antisperm antibody detection: 2 clinical, biological, and statistical correlation between methods. Am. J. Reprod. Immunol. 38, 224-230.

Lynch, DM., Howe, SE.. 1987. Comparison of a Direct and Indirect ELISA for Quantitating Antisperm Antibody in semen. Journal of Andrology, 8, 215-220.

Liu, Y., He, L., 2004. The present status of experimental diagnosis of male infertility and there significance [J]. Chinese Journal of Andrology. 18, 3-5

Leib, Z., Bartoov, B., Eltes, F., Servadio, C., 1994. Reduced semen quality caused by chronic abacterial prostatitis: an enigma or reality? Fertil. Steril. 61, 1109-1116.

Lombardo, F., Gandini, L., Dondero, F., Lenzi, A., 2001. Antisperm immunity in natural and assisted reproduction. Hum. Reprod. Update. 7, 450-456.

Marconi M, Pilatz A, Wagenlehner F, Diemer T, Weidner W. 2009. Are Antisperm Antibodies Really Associated with Proven Chronic Inflammatory and Infectious Diseases of the Male Reproductive Tract? .EUROPEAN. UROLOGY. 56, 708-715.

Rossato, C., Galeazzi, M., Ferigo, C., 2004. Foresta Antisperm antibodies modify plasma 
membrane functional integrity and inhibit osmosensitive calcium influx in human sperm. Human. Reproduction. 19, 1816-1820.

Mayorga Torres, BJM., Cardona-Maya, W., Cadavid, A., Camargo, M., 2013. Evaluación delospará metros funcionales delespermaen individuos infértiles normozooespérmicos. Actas. Urol. Esp. 37, 221-227.

Motrich, RD., Maccioni, M., Molina, R., Kissers, A., Olmedo, J., et al. 2005. Reduced semen quality in chronic prostatitis patients that have cellular autoimmune response to prostate antigens. Hum. Reprod. 20, 2567-2572.

Mie, PX., 2009. The significance of detection antisperm antibody in sperm surface in chronic prostatitis patients. National Journal of Andrology. 15, 750-751.

Motrich, RD., Maccioni, M., Ponce, A., et al. 2006. Pathogenic Conse quences in Semen Quality of an Autoimmune Response against the Prostate Gland: From Animal Model Human Disease [J]. J. Immunol. 177, 957-967.

Mazumdar, S., Levine, AS., 1998. Antisperm antibodies: etiology, pathogenesis, diagnosis, and treatment. Fertil. Steril. 70, 799-810.

Marshburn, PB., Kutteh, WH., 1994. The role of antisperm antibodies in infertility. Fertil. Steril. 61, 799-811.

Mercan R., Oehninger S., Muasher SJ., Toner JP., Mayer J., Lanzendorf SE., 1998. Impact of fertilization history and semen parameters on ICSI outcome. J Assist Reprod Genet 15, $39-45$.

Nagy, ZP., Verheyen, G., Liu, J., Joris, H., 1995. Janssenswillen C, Wisanto A, Devroey P, Van Steirteghem AC. Results of 55 intracytoplasmic sperm injection cycles in the treatment 
of male-immunological infertility. Hum. Reprod. 10, 1775-1780.

Naz, RK., 2011. Antisperm contraceptive vaccines: where we are and where we are going? Am. J. Reprod. Immunol. 66, 5-12,

Oliveros, SY., Mallea, SL., Frontela, NM., Machado, AJ., 2000. Anticuerpos antiespermatozoides enparejas con infertilidad de causa no explicada. Rev. Cubana. Endocrinol. 11, 11-16.

Ohl, DA., Naz, RK., 1995. Infertility due to antisperm antibodies. Urology. 46, 591-602.

Oliveros, SY., Mallea, SL., Frontela Noda M, MachadoCurbelo AJ., 2000. Anticuerpos antiespermatozoides en parejas con infertilidad de causa no explicada. Rev. Cubana. Endocrinol. $11,11-16$.

Pontari, MA., Ruggieri, MR.., 2008. Mechanisms in prostatitis/chronic pelvic painsyndrome. J Urol (Suppl 5) S61-67.

PATRICIA, CG., ELIANA, MR., ODUVALDO, CM., 2007. Antisperm antibodies in infertile men and their correlation with seminal parameters. Reproductive Medicine and Biology. 6, 33-38.

Qin, S., Deng, XQ., Zhang, H., Zhang, R., 2005. The study of semen quality and function change of 154 cases of chronic prostatitis patients. Sichuan Medical Journal. 26, 1430-1431. Rivera, JG., Matte, J., 1971. Fenomenos inmunológicos en la infertilidad. Rev. Clin. Esp. $122,1-4$.

Steen, Y., Forssman, L., Lonnerstedt, E., Jonasson, K., Wassen, AC., Lycke, E., 1994. Anti-sperm IgA antibodies against the equatorial segment of the human spermatozoon are associated with impaired sperm penetration and subfertility. Int. J. Fertil. Menopausal. Stud. 
$39,52-56$.

Sinisi, AA., Finizio, B., Pasquali, D., Scurini, C., Dapuzzo, A., 1993 Bellastella A. Prevalence of antisperm antibodies by Sperm MAR test in subjects undergoing a routine sperm analysis for infertility. Int. J. Androl. 16, 311-314.

Sharp, VJ., Takacs, EB., 2010. Powell CR Prostatitis: diagnosis and treatment. Am. Fam. Physician. 82, 397-406.

Vivas, AG., Lozano, HJ., 2007. Velasco J. Regulacióninmuno-testiculary citocinas. Invest .Clin. 48, 107-121.

Vujisic, S., Lepej, SZ., Jerkovic, L., Emedi, I., Sokolic, B., 2005. Antisperm antibodies in semen, sera and follicular fluids of infertile patients: relation to reproductive outcome after in vitro fertilization. Am. J. Reprod. Immunol. 54, 13-20.

Vivas, AG., Lozano, HJ., Velasco, J., 2007 Regulacióninmuno-testicular y citocinas. Invest Clin. 48, 107-21.

Whitmore, WF., Gittes, RF., 1977. Studies on the prostate and testis as immunologically privileged sites. Cancer. Treat. Rep. 61, 217-222.

Wilson, L., 1954. Sperm agglutinins in human semen and blood. Proc. Soc. Exp. Biol. Med. $85,652-655$.

$\mathrm{Xu}$, JN., 1992. knowledge of prevention and control Prostate disease [M]. Shanghai: Shanghai science press, pp. 2-4.

Zhang, JG., Wang, YL., Zhou, SW., 2004. The effect of Antibiotic treatment of patients with chronic nonbacterial prostatitis, and the change of semen quality National Journal of Andrology, 10, 598-600. 
Zini, A., Fahmy, N., Belzile, E., Ciampi, A., Al-Hathal, N., Kotb, A., 2011. Antisperm antibodies are not associated with pregnancy rates after IVF and ICSI: systematic review and meta-analysis. Hum. Reprod. 26, 1288-1295. 
Records identified through database

searching PuMed $(n=430)$

$\operatorname{EMBASE}(\mathrm{n}=410)$ MEDLINE $(\mathrm{n}=40)$

Cochrane Review $(n=23)$ Science

Direct Elsevier $(n=270)$

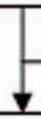

\section{duplicate excluded}

$(n=263)$

Relevant studies for initial identification $(\mathrm{n}=910)$

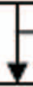

Potentially eligible studies for full-text evaluation $(n=87)$
Titles and abstracts screened Excluded $(n=823)$

Full-text evaluation excluded ( $\mathrm{n}=81$ )

Review article $(n=2)$

Case report $(\mathrm{n}=8)$

Study include in systematic

No control case $(n=18)$

Study was assay serum AsA $(n=5)$

Accompanied by other disorders ( $n=32)$

Chronic prostatitis accompanied

Studies included in

meta-analysis $(n=6)$ infertility $(n=16)$ 
Total Events

Tota

$\begin{array}{llllll}20 & 0 & 20 & 2.6 \% & 5.54 & {[0.25,123.08]}\end{array}$

P.hoover 2012

220

$21 \quad 37$

$19 \quad 310$

$43 \quad 86$

$76 \quad 154$

17

145

2

2
1

11

$2.6 \%$

$5.54[0.25,123.08]$

$11 \quad 8.0 \% \quad 5.91[1.12,31.20]$

$45 \quad 9.8 \% \quad 2.87[0.38,22.00]$

$20 \quad 14.6 \% \quad 5.67[1.55,20.75]$

$30 \quad 30.5 \% \quad 3.90[1.51,10.06]$

Su Qin 2005

Puxin Mie 2009

752

178

$160 \quad 100.0 \%$

$34 \quad 34.3 \% \quad 1.00[0.31,3.18]$

Total $(95 \% \mathrm{Cl})$

Total events

16

Heterogeneity: $\mathrm{Chi}^{2}=5.47, \mathrm{df}=5(\mathrm{P}=0.36) ; \mathrm{I}^{2}=9 \%$

Test for overall effect: $Z=4.14$ ( $P \leq 0.0001)$

$3.26[1.86,5.71]$

\section{M-H, Fixed, 95\% Cl}

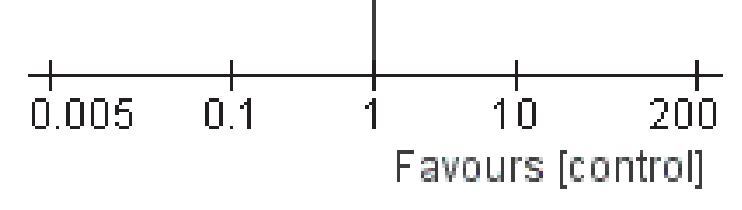




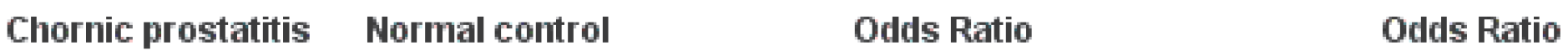

\subsubsection{NIH II}

Hoover P. 2012

Marcoin m. 2009

Mile PK 2009

\section{Subtotal (95\% Cl)}

Total events

Heterogeneity: $\mathrm{Ch}^{\mathrm{z}}=1.79, \mathrm{df}=2(\mathrm{P}=0.41) ; \mathrm{I}^{\mathrm{z}}=0 \%$

Test for overall effect: $Z=0.70(P=0.49)$

\subsubsection{NIH IIla}

Marcoin M. 2009

wie PX 2009

\section{Subtotal (95\% Cl)}

Total events

$\begin{array}{lr}2 & 20 \\ 7 & 42 \\ 0 & 42 \\ & 104\end{array}$

\section{0}

$34 \quad 15.0 \%$

$34 \quad 6.6 \%$

$88 \quad 23.4 \%$

$\begin{array}{ll}3 & 59 \\ 4 & 34 \\ & 93\end{array}$

$45 \quad 4.4 \%$

$34 \quad 14.3 \%$

$79 \quad 18.7 \%$

Heterogeneity: $\mathrm{chi}^{2}=0.30, \mathrm{df}=1\left(\mathrm{P}^{\prime}=0.54\right) ; \mathrm{I}^{2}=0 \%$

Test for overall effect: $Z=0.44(\mathrm{P}=0.66)$

\subsubsection{NIH IIIb}

Marcoin M. 2009

Mie PX. 2009

Subtotal (95\% Cl)

Total events

$2.36[0.24,23.45]$

$1.00[0.23,4.37]$

$1.32[0.39,4.43]$

Heterogeneity: $\mathrm{chi}^{2}=0.49, \mathrm{df}=1(\mathrm{P}=0.49) ; \mathrm{i}^{2}=0 \%$

Test for overall effect: $Z=0.39$ ( $P=0.69$ )

\subsubsection{NIH III}

Marcoin W. 2009

Mie PK 2009

Zhang .10 .2004

Subtotal $(95 \% \mathrm{Cl})$

Total everts

Heterogeneity $\mathrm{chi}^{2}=3.7 \mathrm{~g}, \mathrm{df}=2(\mathrm{P}=0.15) ; \mathrm{l}=47 \%$

Test for overall effect: $Z=2.20(P=0.03)$

\section{Total $(95 \% \mathrm{Cl})$}

Total events

878

Heterogeneity: chi $=7.51, \mathrm{df}=9\left(\mathrm{P}^{\mathrm{P}}=0.58\right)^{\mathrm{F}}=0 \mathrm{~g}$

Test for overall effect: $Z=2.19(\mathrm{P}=0.03)$

Test for subaroun differences: $\mathrm{Ch}^{2}=1.33 \mathrm{df}=3\left(\mathrm{P}=0.72 \mathrm{l}^{2}=0 \%\right.$ 23
$5.54[0.25,123.08]$

$1.50[0.40,5.62]$

$0.26[0.01,6.66]$

$1.46[0.50,4.22]$

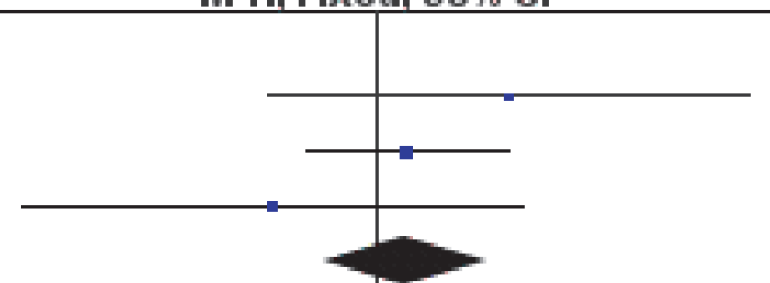

$2.17[0.27,17.37]$

$0.88[0.20,3.84]$

$1.26[0.40,3.99]$
$2.21[0.28,17.31]$

$0.94[0.26,3.36]$

$5.67[1.55,20.75]$

$2.46[1.10,5.51]$

$345100.0 \% \quad 1.75[1.06,2.90]$

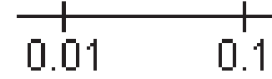

$10 \quad 100$

Favours [experimental] Favours [control] 


\section{Odds Ratio}

Studv or Subgroup

Total Events Total Weight M-H, Fixed, 95\% Cl

\section{Eve}

\subsubsection{Get rid of ELISA test}

Hoover P. 2012

Marcoin W. 2009

Mie PX 2009

Qin S. 2005

Subtotal $(95 \% \mathrm{Cl})$

Total events

Heterogeneity: $\mathrm{Chi}^{2}=3.54, \mathrm{df}=\left.3(\mathrm{P}=0.32)^{2}\right|^{2}=15 \%$

Test for overall effect: $Z=2.72(\mathrm{P}=0.007)$

\subsubsection{Get rid of IBT test}

Deng $\mathrm{CH} .1992$

Marcoin M. 2009

Wie PX. 2009

Qin S. 2005

Zhang .10 .2004

Subtotal $(95 \% \mathrm{Cl})$

Total events

Heterogeneity: $\mathrm{Chi}^{2}=5.33, \mathrm{df}=4(\mathrm{P}=0.25)^{2} \mathrm{I}^{2}=25 \%$

Test for owerall effect: $Z=4.00(P=0.0001)$

\section{Total $(95 \% \mathrm{Cl})$}

\section{1}

$269100.0 \%$

Total events 290 27

Heterogeneity: Chi $^{2}=9.17, \mathrm{df}=8(\mathrm{P}=0.33) ;\left.\right|^{2}=13 \%$

Test for overall effect: $Z=4.82(\mathrm{P}=0.00001)$

Test for subaroun differences: $\mathrm{Ch} \mathrm{i}^{2}=0.27 . \mathrm{df}=1(\mathrm{P}=0.60) . \mathrm{I}^{2}=00 \%$
16

\section{M-H, Fixed, $95 \% \mathrm{Cl}$}

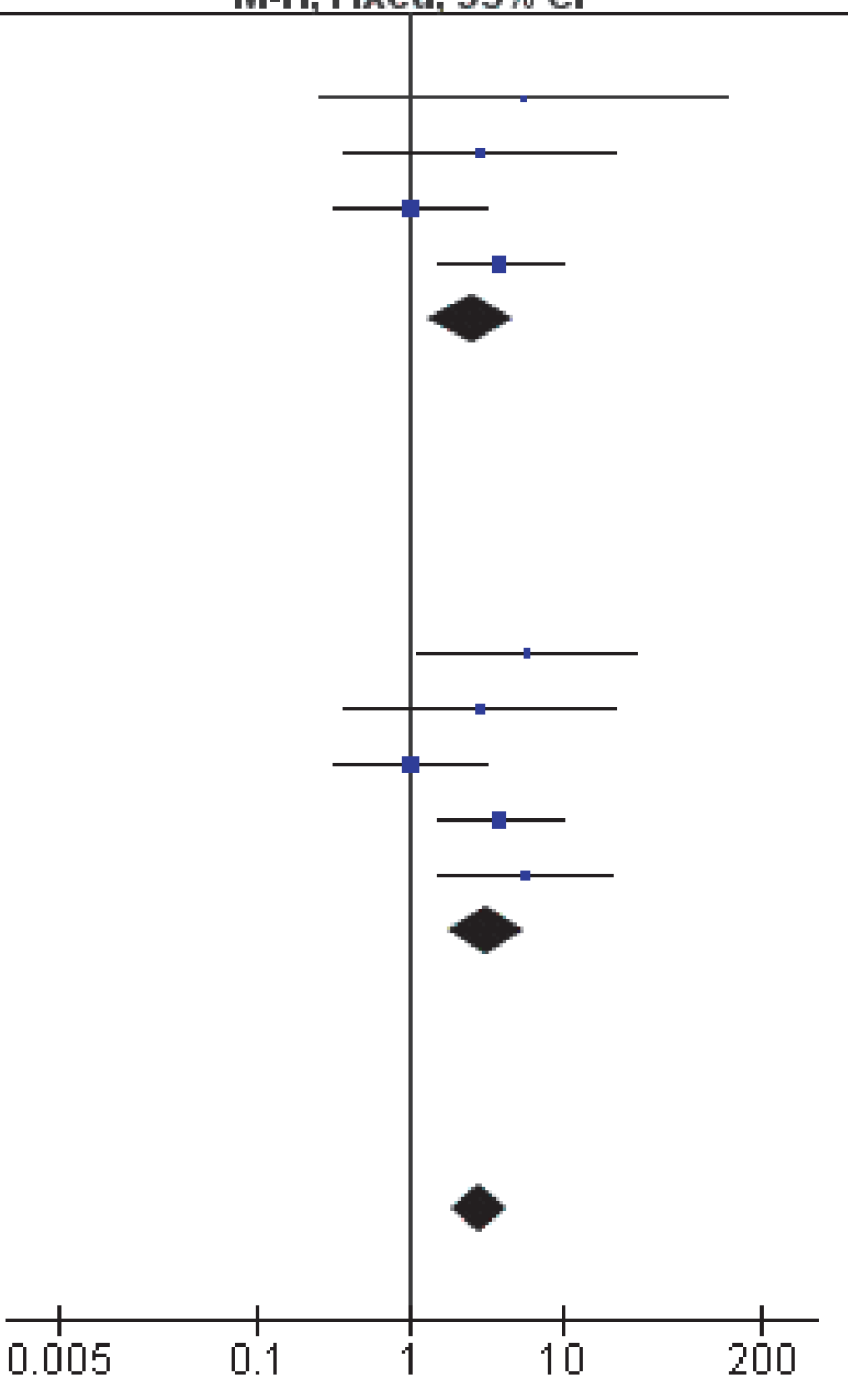

$5.91[1.12,31.20]$

$2.87[0.38,22.00]$

$1.00[0.31,3.18]$

$3.90[1.51,10.06]$

$5.67[1.55,20.75]$

$3.20[1.81,5.66]$
$2.87[0.38,22.00]$

$1.00[0.31,3.18]$

$2.54[1.30,4.96]$

Favours [experimental] Favours [control] 
Begg's funnel plot with pseudo $95 \%$ confidence limits

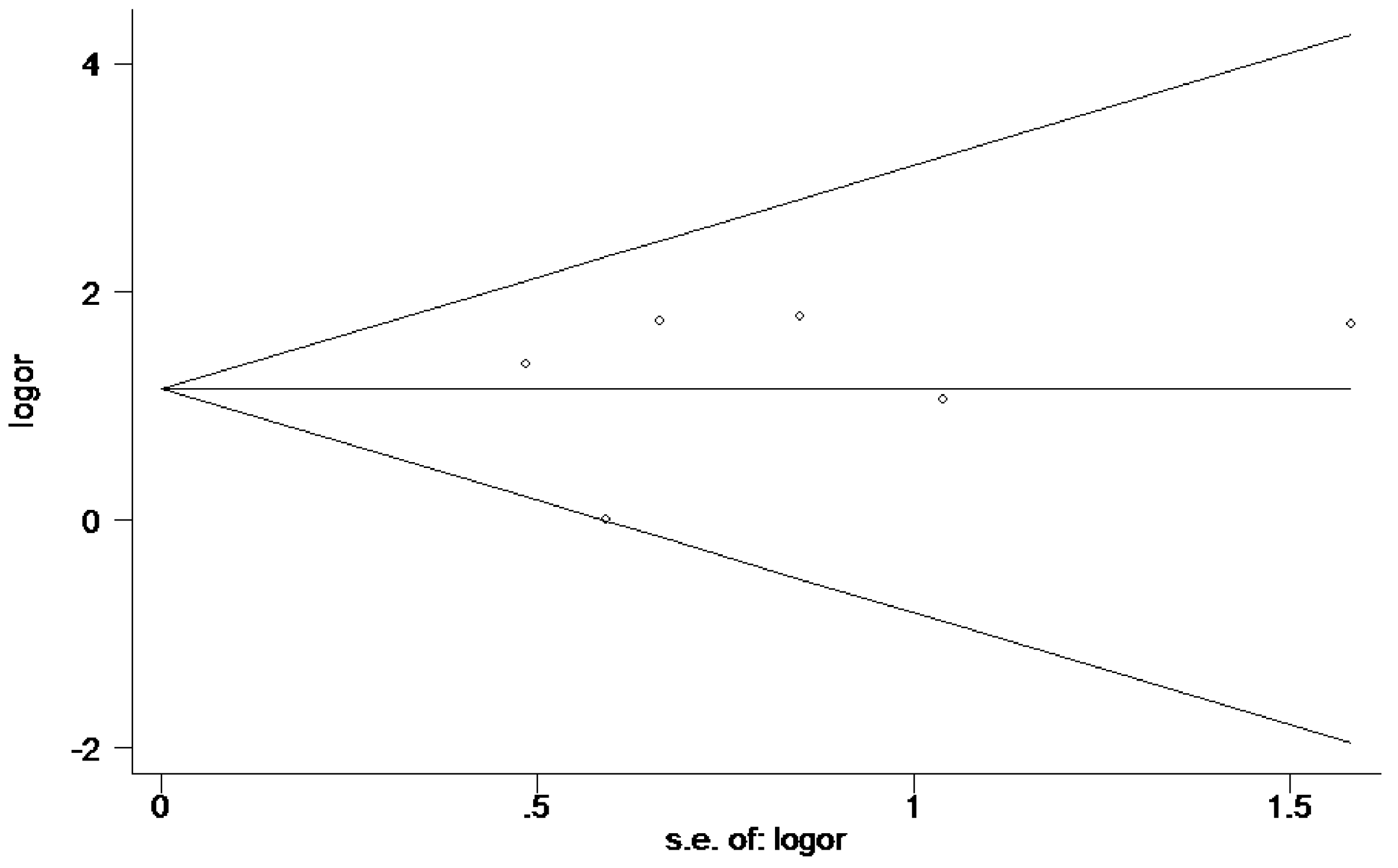


Meta-analysis fixed-effects estimates (linear form)

Study ommited

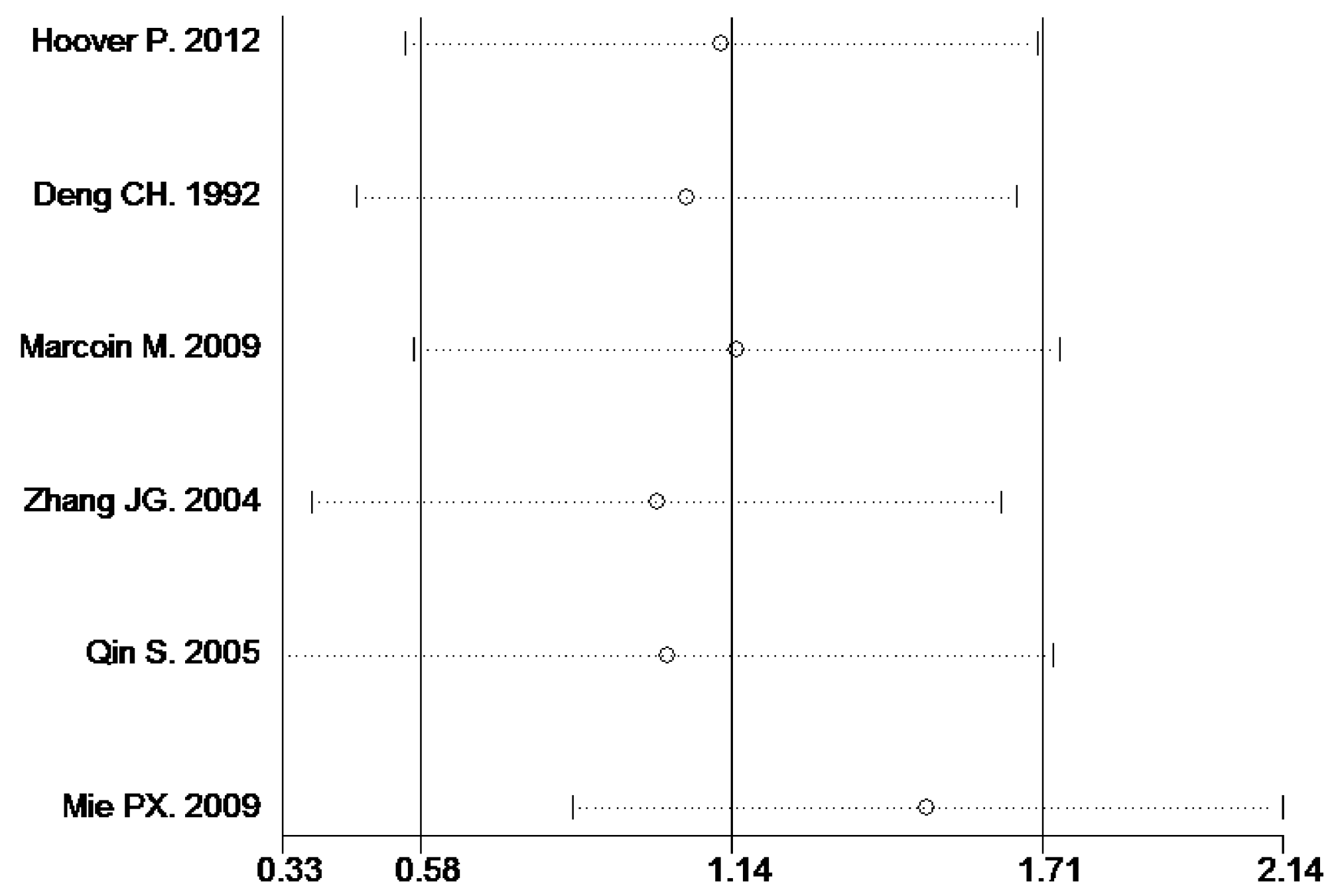

